\title{
Os cientistas em quadrinhos: humanizando as ciências
}

\author{
Scientists in cartoons: humanizing science
}

\section{Carlos Henrique \\ Fioravanti}

Jornalista científico.

Avenida Doutor Cândido Mota

Filho, 183/24

05351-000 - São Paulo - SP - Brasil

chfioravanti@gmail.com

\section{Rodrigo de Oliveira \\ Andrade}

Jornalista científico.

Rua Sargento Osvaldo, 26/124 03069-020 - São Paulo - SP - Brasil rodrigo.oliandrade@gmail.com

\section{Ivan da Costa Marques \\ Professor, Programa de Pós- graduação em História das Ciências e das Técnicas e Epistemologia/ \\ Universidade Federal do Rio de Janeiro. \\ Avenida Atlântica, 822/402 \\ 22010-000 - Rio de Janeiro - RJ \\ - Brasil \\ imarques@nce.ufrj.br}

FIORAVANTI, Carlos Henrique; ANDRADE, Rodrigo de Oliveira; MARQUES, Ivan da Costa. Os cientistas em quadrinhos: humanizando as ciências. História, Ciências, Saúde - Manguinhos, Rio de Janeiro, v.23, n.4, out.-dez. 2016, p.1191-1208.

\begin{abstract}
Resumo
Publicados diariamente de 1994 a 2002 no jornal Correio Popular, de Campinas, os quadrinhos Os cientistas, produzidos por jornalistas e pesquisadores brasileiros, apresentaram a prática científica de modo crítico e irreverente, expondo a insegurança e as frustrações dos cientistas, além dos conflitos entre eles e da dificuldade de comunicação com outros grupos, como os jornalistas. Este artigo mostra a diversidade de personagens, temas, apresentação gráfica e seus possíveis significados, por meio de uma amostra de tiras publicadas nos quatro primeiros anos.

Palavras-chave: Os cientistas (quadrinhos); Correio Popular (jornal); jornalismo científico; representações da ciência.
\end{abstract}

\begin{abstract}
Published daily from 1994 to 2002 in Correio Popular, a Campinas-based newspaper, Os cientistas (The scientists) comic strips produced by Brazilian researchers and journalists presented science critically and irreverently, exposing the insecurities and frustrations of scientists, as well as the conflicts between them and their communication difficulties with other groups, like journalists. This article shows the diversity of personalities, subjects, graphic styles, and potential meanings in a sample of comic strips published in the first four years.
\end{abstract}

Keywords: Os cientistas (comic strips); Correio Popular (newspaper); scientific journalism; representations of science. 
ciência costuma ser apresentada como um mundo misterioso, uma caixa-preta, que Bruno
Latour (2000) tentou abrir várias vezes, examinando seus personagens e seus modos de funcionamento. ${ }^{1}$ Em um estudo pioneiro, Latour e Steven Woolgar (1986) acompanharam uma investigação científica em um laboratório de pesquisas médicas no Instituto Salk, em La Jolla, Califórnia, nos EUA. Em Laboratory life (Vida de laboratório), livro que resultou dessa imersão nos procedimentos, hábitos e crenças das equipes do Salk, eles questionam vários pressupostos do trabalho científico. Latour e Woolgar deixavam os cientistas desnorteados quando lhes perguntavam por que confiavam tanto nos equipamentos que usavam - Não poderiam estar errados? Quem é que havia determinado os parâmetros com que funcionavam? - e por que enfatizavam a produção de artigos científicos. Na introdução desse livro, Jonas Salk, inventor da vacina contra a pólio, cujo laboratório Latour e Woolgar (1986, p.13) estudaram, diz que o público não temeria os cientistas nem esperaria deles mais do que eles são realmente capazes de fazer se pudesse entender como o conhecimento científico é produzido e verificar que a atividade de cientista não tem nada de mais extraordinário do que qualquer outra atividade humana.

Raramente se questiona o mundo da ciência ou se expõem seus conflitos internos, dúvidas e incertezas. Normalmente a ciência é enaltecida e apresentada em tom triunfalista, por meio de descobertas aparentemente revolucionárias, e os cientistas, vistos como seres altruístas. Essa visão simplista baseia-se em uma concepção equivocada da ciência como um processo isento de incertezas, conflitos e interesses (Fioravanti, 2013). Neste artigo revelamos uma experiência que, como a investigação de Latour e Woolgar, mostra os conflitos e os impasses do mundo interno da ciência: os quadrinhos Os cientistas, produzidos por jornalistas e pesquisadores brasileiros e publicados diariamente de 1994 a 2002 no jornal Correio Popular, de Campinas, no estado de São Paulo. Destacamos a diversidade de personagens, temas e recursos gráficos, com base em uma amostra de tiras publicadas nos quatro primeiros anos. Não pretendemos analisar as relações entre as linguagens das ciências e as linguagens dos quadrinhos. Também procuramos não ver as tiras como representações dos cientistas, mas sim como descrições de suas performances. Colocar os cientistas em cena por meio de quadrinhos é, por si só, contaminar com sentimentos e humanismos, em especial com humor, a pureza buscada e precisamente nunca alcançada de modo perfeito pelas linguagens científicas (Shapin, 2010).

\section{Ênfase pedagógica}

As revistas de histórias em quadrinhos (HQs) tratam em geral de ficção científica, exaltando os poderes de super-heróis como Homem-Aranha, Super-Homem, Hulk, Capitão América, Flash e Surfista Prateado. A relação entre ciência e HQ se intensificou depois da Segunda Guerra Mundial e nas décadas de 1960 e 1970, durante a corrida espacial, liderada pelos EUA e pela URSS, explorando com liberdade conceitos da física como movimento, força, resistência e velocidade (Gonzaga et al., 2014). Por integrar imagem e texto de modo sintético, a linguagem das HQs tem sido um recurso útil para explicar temas científicos complexos. Em 2015, a Science publicou em HQ um guia da Teoria da Relatividade Geral "tão elegante que não requer superpoderes para ser compreendida", segundo a revista (Cho, 2015). 
Experiências usando histórias em quadrinhos para tratar da ciência são raras no Brasil. A revista Ciência Popular, que circulou de 1948 a 1960, publicava artigos, notícias, HQs e textos ilustrados com explicações sobre conceitos científicos (Silva, 2009, p.66). Outra iniciativa foi Ciências em Quadrinhos, revista lançada em outubro de 1953 pela Editora Brasil-América Limitada (Ebal) como parte de sua estratégia de responder às críticas de que os quadrinhos seriam prejudiciais às crianças, por meio da apresentação de temas educativos em quadrinhos; Ciências em Quadrinhos circulou até setembro de 1958 (Barbosa, 2006). Em 2004, para tratar de problemas ambientais da Amazônia, o cartunista Eunuquis criou o personagem Caboquinho, que saiu como revista de quadrinhos e foi mostrado em uma exposição promovida pelo Instituto Nacional de Pesquisas da Amazônia, em Manaus, em 2014 (Inpa..., 22 abr. 2014). O livro Sim, nós temos cientistas!, de 2012, usou a linguagem das HQs para apresentar cientistas brasileiros do passado ao público infantojuvenil (Motta, 7 fev. 2013).

Um traço comum das HQs nacionais centradas na ciência é a preocupação didáticopedagógica: fazer o leitor entender conceitos científicos ou conhecer personagens importantes da ciência nacional. Caruso e Silveira (2009) apresentaram um método de trabalhar conceitos de ciências, saúde, história e sociologia, entre outras áreas, por meio de HQs produzidas pelos próprios alunos de escolas públicas de ensino médio do Rio de Janeiro. Outras iniciativas tratam da origem e prevenção de doenças como a hanseníase (Cabello, De La Roque, Souza, 2010) e os efeitos das mudanças do clima (Galhardo, Meiguins, 2014). Ao tratar de ciência com finalidades pedagógicas, as HQs reforçam o que Latour chama de modelo de difusão. Tal modelo implica a separação de cientistas que permanecem dentro do laboratório, enquanto do lado de fora se mantêm políticos, investidores, advogados, jornalistas, colegas acadêmicos e usuários do trabalho científico (Latour, 2000, p.258-262). Essa visão justificaria duas expressões tão comuns quanto temerárias: o "analfabetismo científico" e a "percepção pública da ciência", que acentuam a separação entre especialistas e não especialistas. JeanMarc Lévy-Leblond (2006, p.32) observa:

quando usamos a expressão 'percepção pública da ciência' (public understanding of science), dividimos automaticamente a humanidade em público leigo 'ignorante', de um lado, e 'nós', os sábios cientistas, de outro. Entretanto, uma das principais características do nosso tempo é justamente o fato de que essa dicotomia deixou de existir. Nós, cientistas, não somos basicamente diferentes do público, salvo no campo bem delimitado da nossa especialização (destaques no original).

Uma análise de reportagens sobre genoma e organismos geneticamente modificados - os chamados transgênicos - publicadas no Brasil de 2000 a 2004 indicou que a ideia de deficit científico está associada à noção de atraso, justifica as ações dos cientistas como forma de superar o descompasso entre países ricos e pobres e

reserva-se o direito de dividir a sociedade entre aqueles que podem ou não opinar sobre assuntos de Ciência \& Tecnologia (C\&T), como se a percepção e a compreensão da ciência passassem somente pelo nível da alfabetização do ponto de vista do vocabulário da ciência, e não pela percepção e consciência de sua estrutura social e seus impactos (Kanashiro, Evangelista, 2004, p.4). 
Outra abordagem, a de tradução/translação, que se afasta do chamado modelo do deficit, implica uma visão mais ampla e participativa de C\&T: a ciência não é mais feita apenas por cientistas, nem a tecnologia apenas por tecnólogos, mas, sim, por eles e por uma multidão de anônimos que lhes dá suporte, dinheiro e condições de trabalho (Latour, 2000, p.233-234).

Uma iniciativa internacional que merece ser mencionada - e, sem finalidades pedagógicas, explora os conflitos de pesquisadores entre eles e com os integrantes das equipes que coordenam - é a PhD, abreviação de Piled higher and deeper (empilhados mais alto e mais fundo, em uma tradução aproximada). Trata-se de uma tira, "about life (or the lack thereof) in Academia" (sobre a vida [ou falta dela] na academia), que começou a ser publicada em outubro de 1997 em um jornal de estudantes da Universidade Stanford, nos EUA, e retrata os conflitos entre estudantes e seus colegas, professores e orientadores acadêmicos. Criada pelo engenheiro mecânico Jorge Cham, $P h D$ é publicada em jornais e revistas impressas e on-line no site PhD Comics, ${ }^{2}$ que recebe mais de sete milhões de visitantes por ano. Ao expor o dia a dia dos pesquisadores nos laboratórios de pesquisa científica, Os cientistas constitui uma experiência brasileira equivalente, detalhada e analisada a seguir.

\section{Obra coletiva}

Em $1^{\circ}$ de junho de 1994, o Correio Popular, principal jornal de Campinas, então com setenta mil exemplares aos domingos, começou a publicar diariamente as tiras intituladas Os cientistas, obra conjunta de jornalistas em colaboração com pesquisadores, retratando a ciência com humor e crítica (Freitas, 31 maio 1994, p.2). A iniciativa refletia a visão editorial e o interesse por assuntos científicos do então editor geral do jornal, Wilson Marini, que havia trabalhado antes na Revista Brasileira de Tecnologia, publicada pelo Conselho Nacional de Desenvolvimento Científico e Tecnológico (CNPq). A decisão era coerente também com a própria cidade, já que Campinas é um polo de empresas de alta tecnologia e abriga duas universidades de prestígio, a Universidade Estadual de Campinas (Unicamp), a Pontifícia Universidade Católica de Campinas (PUC-Campinas) e outras instituições de ensino superior.

O autor explícito das tiras era o cartunista João Antônio Rodrigues Garcia, que trabalhava como jornalista no Instituto de Pesquisas Tecnológicas do estado de São Paulo. Essa posição lhe conferia um olhar privilegiado sobre os hábitos, as prioridades e as dificuldades diárias dos pesquisadores, que inspiravam as tiras. Outros jornalistas e pesquisadores apresentavam situações que serviam de temas para as tiras; um dos autores deste artigo (Fioravanti), na época trabalhando como repórter de ciência na revista Globo Ciência, participou da criação dos personagens e da elaboração dos roteiros das tiras nos quatro primeiros anos de publicação. A assinatura das tiras, Jão \& Cols, reflete essa colaboração: Jão era o nome artístico de João Garcia, e Cols, colaboradores, embora à primeira vista pudesse parecer outra pessoa. A multiplicidade de visão sobre a ciência dos integrantes da equipe assegurava a diversidade de temas e de personagens, como se verá a seguir.

A publicação de Os cientistas em quadrinhos foi noticiada pelo Correio Popular, quando as tiras começaram a sair e quando se completou um ano de publicação, e pelas revistas Imprensa (Ciência..., dez. 1994) e Globo Ciência (Um ano..., jul. 1995; Informática..., fev. 1996). As tiras foram mostradas em exposições realizadas na Pontifícia Universidade Católica 
de São Paulo (PUC-SP) durante a reunião anual da Sociedade Brasileira para o Progresso da Ciência (SBPC), em 1996, e na Biblioteca Comunitária da Universidade Federal de São Carlos (UFSCar), em 1998.

O Correio publicou quase três mil tiras de Os cientistas (Zanchetta, 2005, p.12), sempre no alto da coluna dos quadrinhos, acima das tiras traduzidas, até 2002, quando sua publicação cessou devido a reformulações orçamentárias e editoriais decorrentes da saída do editor geral do jornal. Depois disso, Os cientistas, publicados apenas (mas não de modo exclusivo) no Correio, não encontraram outros espaços que permitissem sua expansão e continuidade, como a maioria das tiras publicadas em muitos jornais ao mesmo tempo.

Os cientistas reemergiram em um livro de vinte páginas (Jão, 2005), em um blog 3 e em uma exposição integrante da semana nacional de C\&T, promovida pelo governo federal (Garcia, 21 out. 2009). Alguns personagens tornaram-se assíduos a partir de 2009 no Folhinha, suplemento infantil do jornal Folha de S.Paulo (Os Cientistas..., 21 fev. 2009), em situações mais simples e amenas que as publicadas no Correio Popular. Os quadrinhos Os cientistas continuam a ser publicados no blog de Garcia e no site da Revista Eletrônica de Jornalismo Científico ComCiência, com frequência menor que a do Correio de Campinas.

\section{Conflitos e intrigas}

Os cientistas abriram a caixa-preta e revelaram o mundo interno da ciência. As situações descritas apresentavam algo raramente exposto: a ciência - e o espaço acadêmico - como um espaço de lutas e competição, um "lócus de afrontamentos visando conservar ou transformar as relações de força - a posição ocupada na estrutura - entre os pesquisadores dotados de recursos diferentes, tanto aqueles científicos quanto os extracientíficos" (Hey, 2008, p.53).

Dr. Ego era quem mais expressava a busca de capital simbólico, fundamentado no acúmulo de cargos e títulos que conferem prestígio, notoriedade e o reconhecimento aos cientistas acadêmicos (Bourdieu, 2004, p.26; Hey, 2008, p.54). Por se apegar à pompa, parecia-lhe inadmissível ser chamado de "bicheiro", em vez de "zoólogo", e ser atingido por um raio em aparente resposta aos seus comentários de que os cientistas seriam os deuses do século XX, em duas situações que expressavam seu esforço em manter o poder.

Atitudes altivas representam uma decorrência perversa ou uma tradução do fato de a ciência só discutir suas questões em seus próprios termos. Um cientista que queira participar de uma discussão científica, discordando de posições estabelecidas, de modo a conquistar um espaço próprio, precisa de um contralaboratório, um espaço de construção de argumentos, pelo menos tão equipado quanto os laboratórios dos demais participantes da controvérsia. O embate cria grupos isolados e privilegiados de pessoas envolvidas na construção de argumentos científicos, defendidos com arrogância e presunção para se evitar o risco de se perderem as posições conquistadas (Latour, 2000, p.131-132). Por trás da persona autoconfiante de Dr. Ego, porém, havia um ser carente e inseguro. "Que falta você me faz, mamãe", ele disse, pensando nos elogios que a mãe poderia lhe fazer em um momento em que certamente necessitava de consolo (Figura 1).

No mundo real, raramente os cientistas são apresentados com suas contradições. Como exemplo, Friedman e Friedland (2006, p.74) descreveram Louis Pasteur (1822-1895) como 
um autêntico francês: temperamental, egoísta, obsessivamente profundo ... excepcionalmente propenso a se valer de descobertas feitas por acaso ... Assustadoramente egoísta, relutante em reconhecer os feitos de seus predecessores e contemporâneos, às vezes um tanto desonesto, um exibicionista declarado e (paradoxalmente) inimigo ferrenho dos médicos - apesar disso tudo, é pouco provável que a França venha a ter outro cientista tão ilustre como ele.

Geison (2002, p.45-68) faz um retrato ainda mais profundo e crítico de Pasteur, apresentado como um cientista tão talentoso e tenaz quanto despótico e ávido pela fama. ${ }^{4}$

O egocentrismo de Dr. Ego contrastava com o altruísmo que a maioria dos 162 moradores de Campinas entrevistados em um inquérito atribuiu como traço de personalidade predominante dos cientistas (Vogt, Evangelista, Knobel, 2003). A imagem mais comum dos cientistas ligava-se a outro personagem, Vitório, pesquisador jovem e passional preocupado com a realidade social
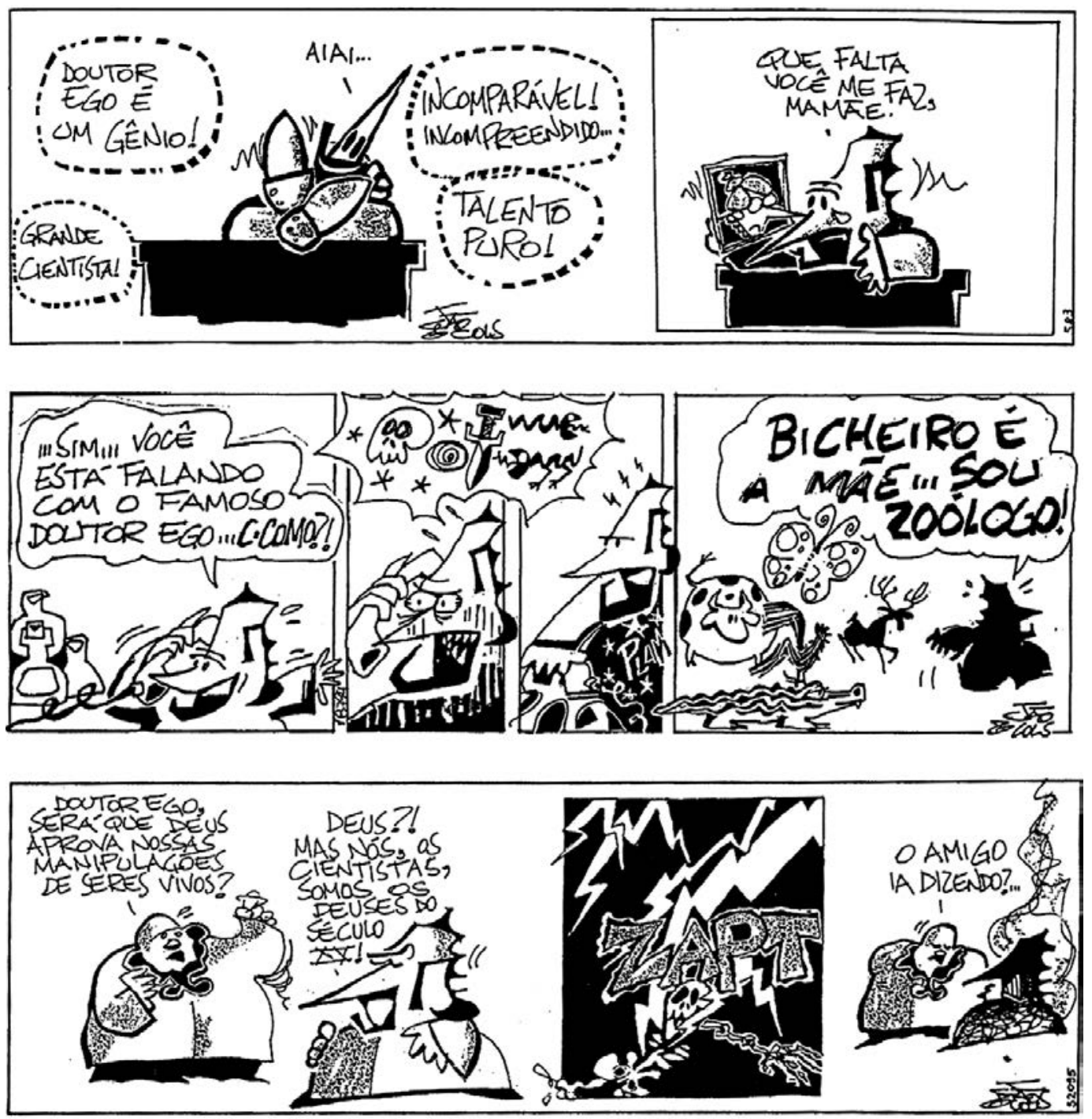

Figura 1: Tiras de João e Cols publicadas em Correio Popular, Campinas, 1994-2002 
do país. No entanto, ele não era capaz de fazer seu trabalho e, enfim, de fazer a construção de fatos e artefatos científicos ser usada para amenizar os problemas sociais. O resultado era o sarcasmo expresso nos constantes conflitos com Dr. Ego, por causa das visões de mundo divergentes. Um dia, cheio de esperança, Vitório comentou que os cientistas brasileiros iriam anunciar a cura da Aids. Dr. Ego retorquiu: "Nesse dia vão descobrir que os elefantes voam, Vitório!" Em um comentário dotado de rara honestidade e desesperança, Dr. Ego reconhecia que os espaços e os argumentos construídos em espaços geopolíticos periféricos dificilmente conseguem se impor à superioridade de equipes maiores, mais ágeis, mais organizadas e com financiamentos maiores dos centros de pesquisa de países ricos (Latour, 2000, p.371).

Dr. Ego pensava como um cientista de país rico. Quando Vitório comentou angustiado: "Mais de um terço das famílias brasileiras vivem em favelas... e nós aqui, pedindo para consertar um espectrômetro de massa", ele resolveu o problema de imediato, sugerindo que comprasse um equipamento novo. O comentário irônico expressava a visão da produção científica em países ricos, nos quais o custo para comprar um equipamento novo era menor do que o de consertar um antigo. Vitório parece não ter aliados em seu desejo de gerar benefícios para o país com seu trabalho. Quando ele perguntou se Lerdo amava o Brasil, Lerdo respondeu: "Só nas férias" (Figura 2).

Lerdo, o burocrata, personificava a resistência ao trabalho científico, indicando que nem sempre as competências se complementavam (Latour, 2000, p.258). Lerdo raramente aceitava sem contestações os pedidos dos pesquisadores; impedia até involuntariamente o andamento das pesquisas; com facilidade se tornava um déspota quando contrariado; adorava privilégios e aceitava com naturalidade a troca de favores. Desdenhava os cientistas, que, para ele, procuravam a verdade em lugares errados e não onde, a seu ver, estava: no Diário Oficial. "Não sou como vocês", disse ele em uma das tiras, expressando como seu mundo, o da burocracia, estava supostamente distante dos espaços e dos valores dos cientistas (Figura 3). No entanto, um mundo depende do outro, pois os cientistas só conseguem construir e manter seus laboratórios porque "outras pessoas estão trabalhando mais ou menos em favor do mesmo objetivo" (Latour, 2000, p.258).

Os cientistas mostraram os problemas da disseminação dos computadores pessoais, no início da década de 1990, por meio do conflito entre pesquisadores mais antigos e mais jovens. Zago expressava a persistência e a boa vontade associadas à produção científica. Procurava ser reconhecido pelo trabalho sério, mas passava como ingênuo, por não dominar as novas tecnologias, diante do estagiário Interneto, cuja habilidade em informática o fazia parecer arrogante. Um dia, Zago sofria para aprender a lidar com os computadores e mostrou um machado a Interneto, como se quisesse golpeá-lo; Zago lhe perguntou se ele sabia o que era aquele objeto, e Interneto respondeu prontamente: "Algum acessório de seu computador?" Quando Zilda, colega de Zago, perguntou se Interneto sabia como resolver um problema no computador dela, o geniozinho respondeu: "Não sei, mas já lhe ensino."

Zilda vivia o duplo papel de cientista e mãe, cuidando de seu trabalho e de seu filho curioso, Zildinho, que levava o leitor para outros espaços - a casa e a escola -, alertando sobre as pessoas que podem nunca ter entrado em um laboratório, mas podem ser indiretamente importantes na construção dos fatos científicos, como políticos, homens de negócios e professores (Latour, 2000, p.259-261). Uma das tiras apresentava Zildinho e um colega aparentemente em uma 

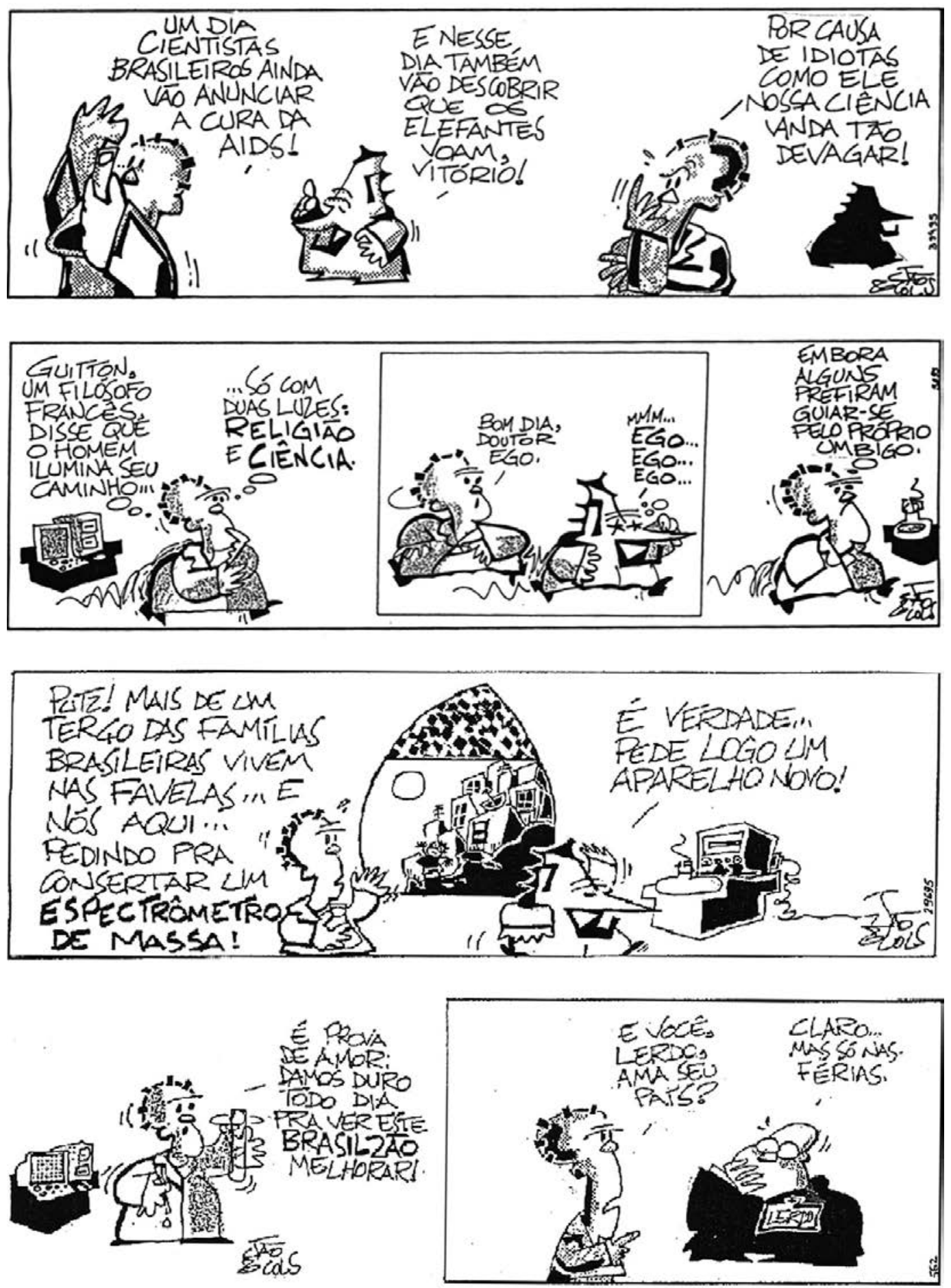

Figura 2: Tiras de João e Cols publicadas em Correio Popular, Campinas, 1994-2002 

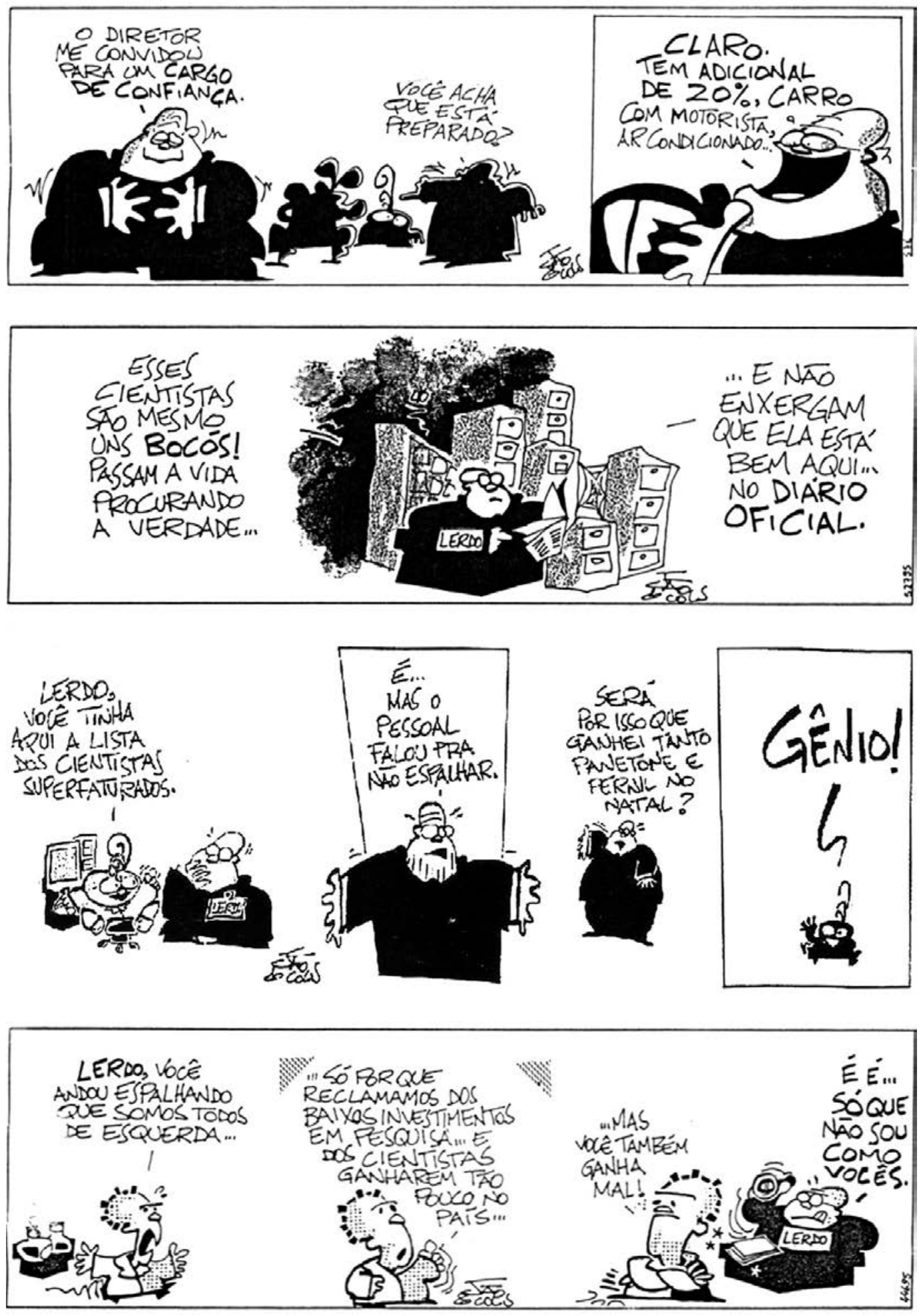

Figura 3: Tiras de João e Cols publicadas em Correio Popular, Campinas, 1994-2002 
aula de ciências, um deles questionando-se, em uma redação cheia de erros gramaticais, por que o Brasil estaria em $30^{\circ}$ lugar em ciência no mundo. Dessa situação pode também ser feita a inferência de que não é possível se destacar na produção de ciências sem uma base educacional e uma sólida base de conhecimentos da nossa língua, o português, disseminada por toda a população (Figura 4).

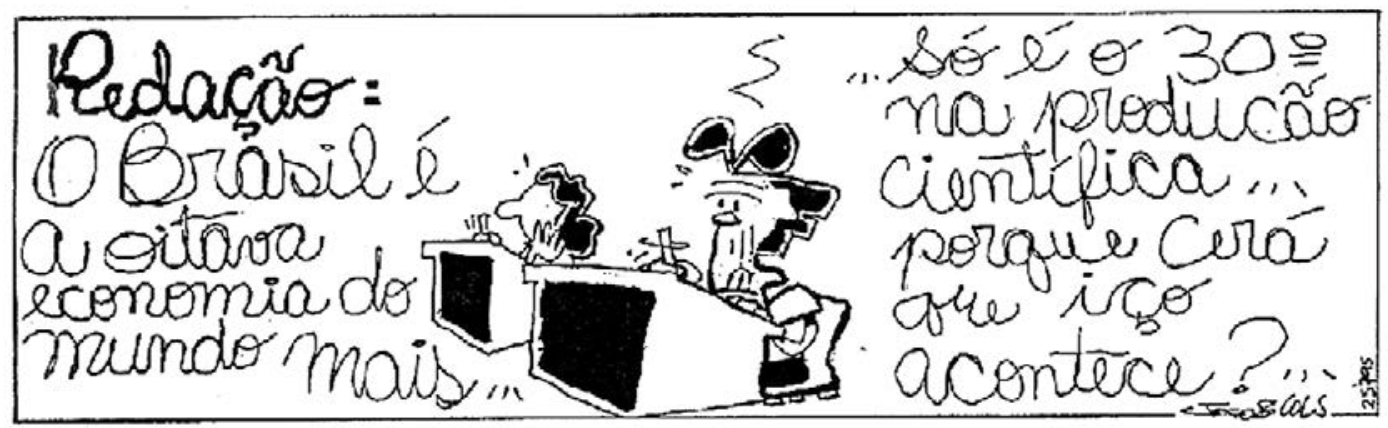

Figura 4: Tiras de João e Cols publicadas em Correio Popular, Campinas, 1994-2002

\section{Os desastres das (inevitáveis) traduções}

Há muitos riscos na tradução - a transposição de uma língua para outra - e na translação - a construção de novas interpretações - do conhecimento científico, uma vez que cientistas especializados em suas áreas, mas com prática limitada em se comunicar com outros grupos sociais, arriscam contar sobre seu trabalho a grupos não especializados em ciência, como os jornalistas. Podemos dizer que, tanto quanto historiadores, economistas, sociólogos e antropólogos, os jornalistas tentam abrir as caixas-pretas da ciência para os cidadãos comuns darem uma olhada, ainda que nem sempre os instrumentos conceituais para concretizar esse objetivo estejam disponíveis em seus respectivos campos disciplinares, já que em geral as disciplinas dos saberes ocidentais não atravessam o hiato epistemológico que separa a natureza da sociedade (Latour, 2000, p.34, 194).

A assimetria de poder e a falta de prática de interação levavam a resultados inesperados e decepções. Em uma das tiras de Os cientistas, Dr. Ego se indignou ao ver que suas observações tinham sido publicadas de modo equivocado em um jornal. Vitório comentou que ele só tinha falado "cientifiquês" e que da próxima vez deveria "falar como gente". Zilda, embora provavelmente tivesse mais habilidade em atender aos jornalistas, gostou do resultado de uma entrevista, a não ser por um comentário negativo sobre a foto em que aparecia.

Várias tiras expressaram a divergência de prioridades entre jornalistas e cientistas, como quando Dr. Ego reclamou que os jornalistas só procuravam os cientistas para falar sobre "banalidades", como drogas e epidemias. Em resposta, Vitório disse que os jornalistas de fato tinham se esquecido de "seu minucioso estudo sobre os tesourinhos de Magadascar". Essa era também uma crítica aos jornalistas, que, em busca do episódico e do sensacional, se interessavam "mais pelo jogo e pelos jogadores do que por aquilo que está em jogo" (Bourdieu, 1997, p.135), com frequência propagando notícias sobre fatos exóticos e irrelevantes, que não refletiam a produção científica. Dr. Ego também temia a imprensa, que poderia revelar suas falcatruas (Figura 5). 

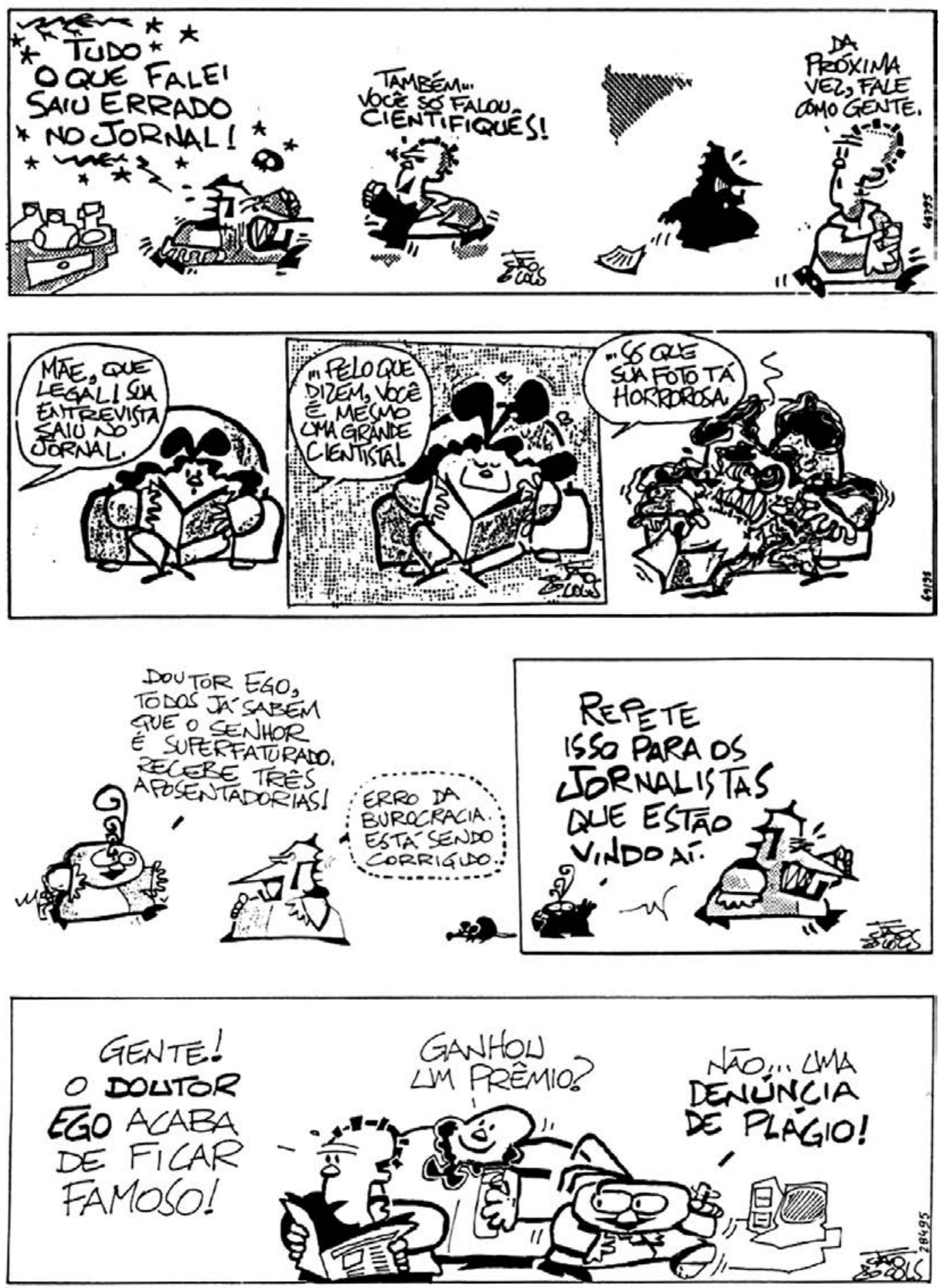

Figura 5: Tiras de João e Cols publicadas em Correio Popular, Campinas, 1994-2002

Os cientistas inovaram graficamente ao mesclar linguagens, apresentando situações ora em uma única cena, como nos cartuns, ora em quadros, como nas histórias em quadrinhos. Várias tiras de cena única se apoiaram em pinturas clássicas. Em uma delas, ironizando o distanciamento dos cientistas de outros grupos sociais, com base em uma pintura de Rugendas, Dr. Ego anunciou uma forma de estar mais próximo do povo, sendo carregado como um antigo 
senhor de engenho. Outra tira, a partir de Os retirantes, de Candido Portinari (1903-1962), expressou a avidez de migrantes pobres que entraram em um laboratório e perguntaram se a ciência feita ali "serve pra gente comer?" (Figura 6).
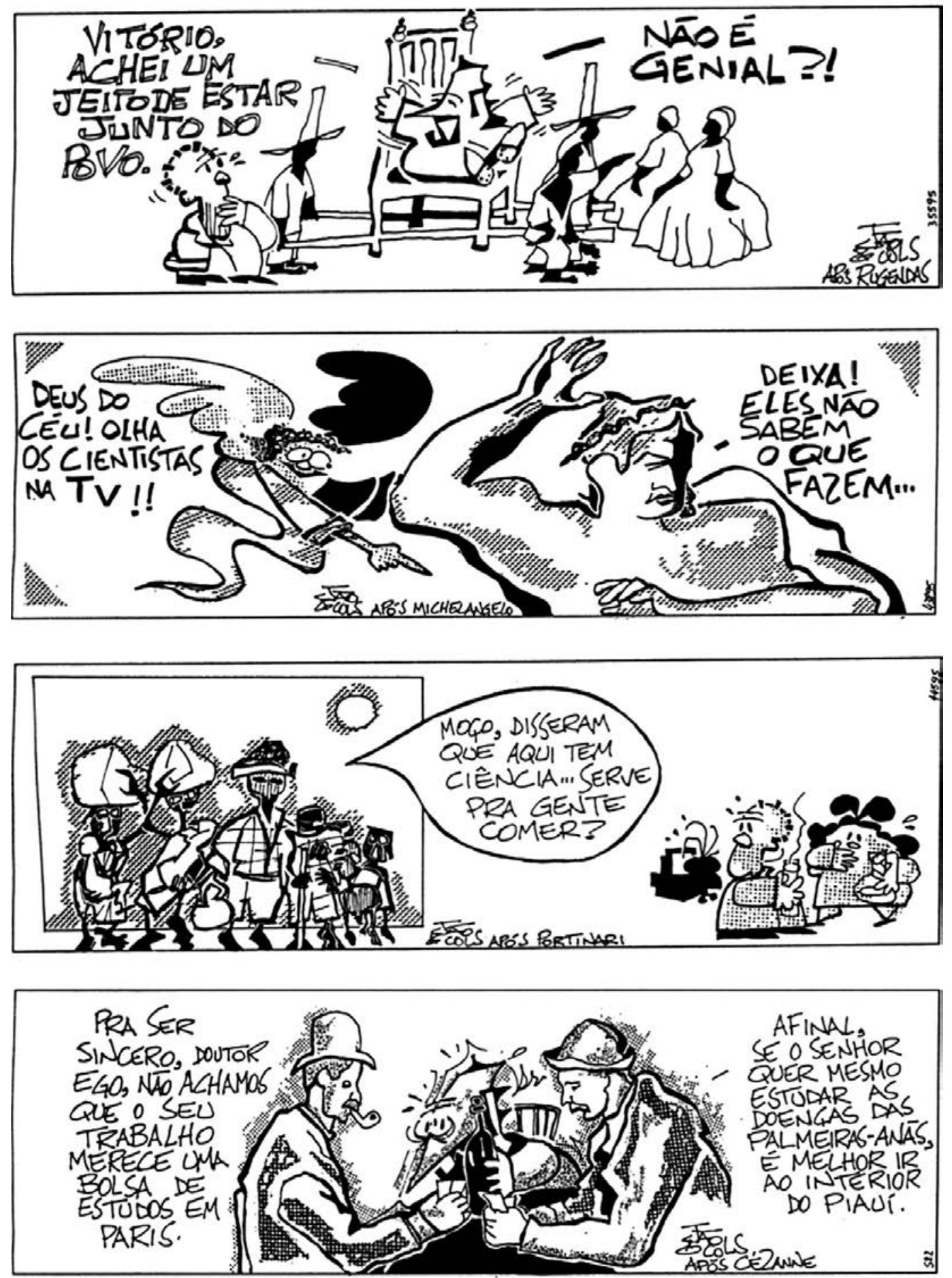

Figura 6: Tiras de João e Cols publicadas em Correio Popular, Campinas, 1994-2002 
Em outra vertente, com extrema concisão gráfica, ganharam voz atores não humanos como vírus, fungos e até mesmo uma molécula de DNA, também em conflitos entre eles ou com os seres humanos. Embora pudessem colaborar, os representantes do mundo microscópico, nas tiras, revelavam um grau acentuado de voluntarismo e impulsividade, expressando uma simplificação necessária para a limitação de tempo e de espaço dos episódios apresentados, e em geral ludibriavam os seres humanos, como os micróbios fizeram inicialmente com Louis Pasteur na contenda sobre a geração espontânea com Félix Pouchet (Latour, 2000, p.138-139, 210, 214).

Em uma das tiras, os vírus ebola comentaram com altivez que os cientistas os consideram desaparecidos, embora estivem prontos para reaparecer - e de fato reemergiram anos depois. Os seres do mundo microscópico se apresentavam como seres rebeldes e voluntariosos, capazes de brincar com células supostamente humanas, mas também sensíveis, como a molécula de DNA sentindo-se invadida ao ser tão examinada pelos cientistas (Figura 7).

\section{Desensinar e desconstruir}

Os cientistas diferenciam-se de outras iniciativas nacionais descritas anteriormente por não ter preocupação pedagógica, por passar ao largo das habitualmente aplicadas noções de "analfabetismo científico" e "deficit científico" e por questionar crenças estabelecidas. Ao aplicar um conceito científico enquanto subia o Corcovado, Lerdo concluiu que o peso aumentava com o tempo e a distância, mas poderia diminuir com a velocidade. A expectativa de idealismo esvaiu-se quando um rapaz explicou a Zago que queria um estágio em seu laboratório porque, depois de bater muitos carros, o pai dele queria que ele ficasse "longe da grana"; a vocação científica tornava-se então uma escolha circunstancial, não um propósito em si, e refletia o elitismo dos estudantes universitários que ingressavam na carreira científica. Do mesmo modo, a descoberta científica não era apenas uma fonte de alegria, mas também de angústia, a ponto de Zilda pedir a Zago que mostrasse estarem errados no que haviam feito (Figura 8).

Ao testemunhar cenas indiscretas, como se acompanhasse o dia a dia dos pesquisadores por uma câmara oculta nos laboratórios ou nos corredores dos centros de pesquisa, o leitor usufrui da imagem como fonte de informação, como um historiador (Meneses, 2003), e se torna um observador da ciência, que pode se decepcionar e se surpreender ao ver o que queria ver ou o que não queriam que visse. Os cientistas tacitamente valorizavam o modelo de translação, interativo e participativo, em vez do habitual modelo de difusão.

As tiras expuseram com irreverência as entranhas da ciência e as prioridades científicas, muitas vezes centradas em interesses personalistas, os valores morais nem sempre enaltecedores, os hábitos e as dificuldades diárias dos pesquisadores em seu ambiente de trabalho, mais do que suas realizações. Desse modo, ressaltavam as fraquezas e os aspectos puramente humanos, como o egocentrismo e as frustrações, diferentemente da abordagem clássica da divulgação científica, que exalta as façanhas e o poder dos pesquisadores, omitindo suas fragilidades, incertezas e frustrações (Fioravanti, 2013). Emergia daí uma visão cética e cínica do mundo da ciência, uma vez que sugeria que os sonhos e os planos dificilmente se realizariam, em vista dos obstáculos a enfrentar. 

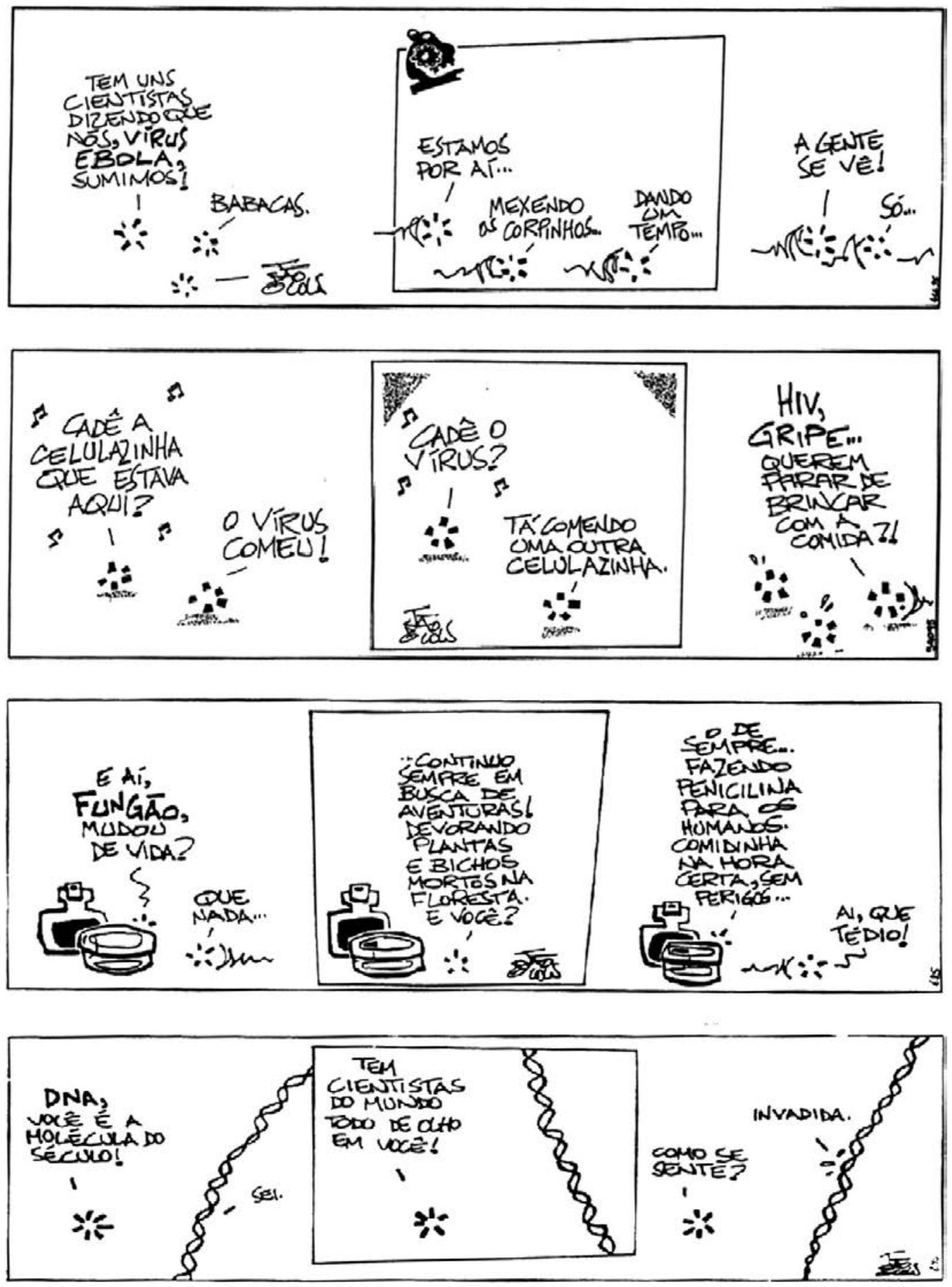

Figura 7: Tiras de João e Cols publicadas em Correio Popular, Campinas, 1994-2002 

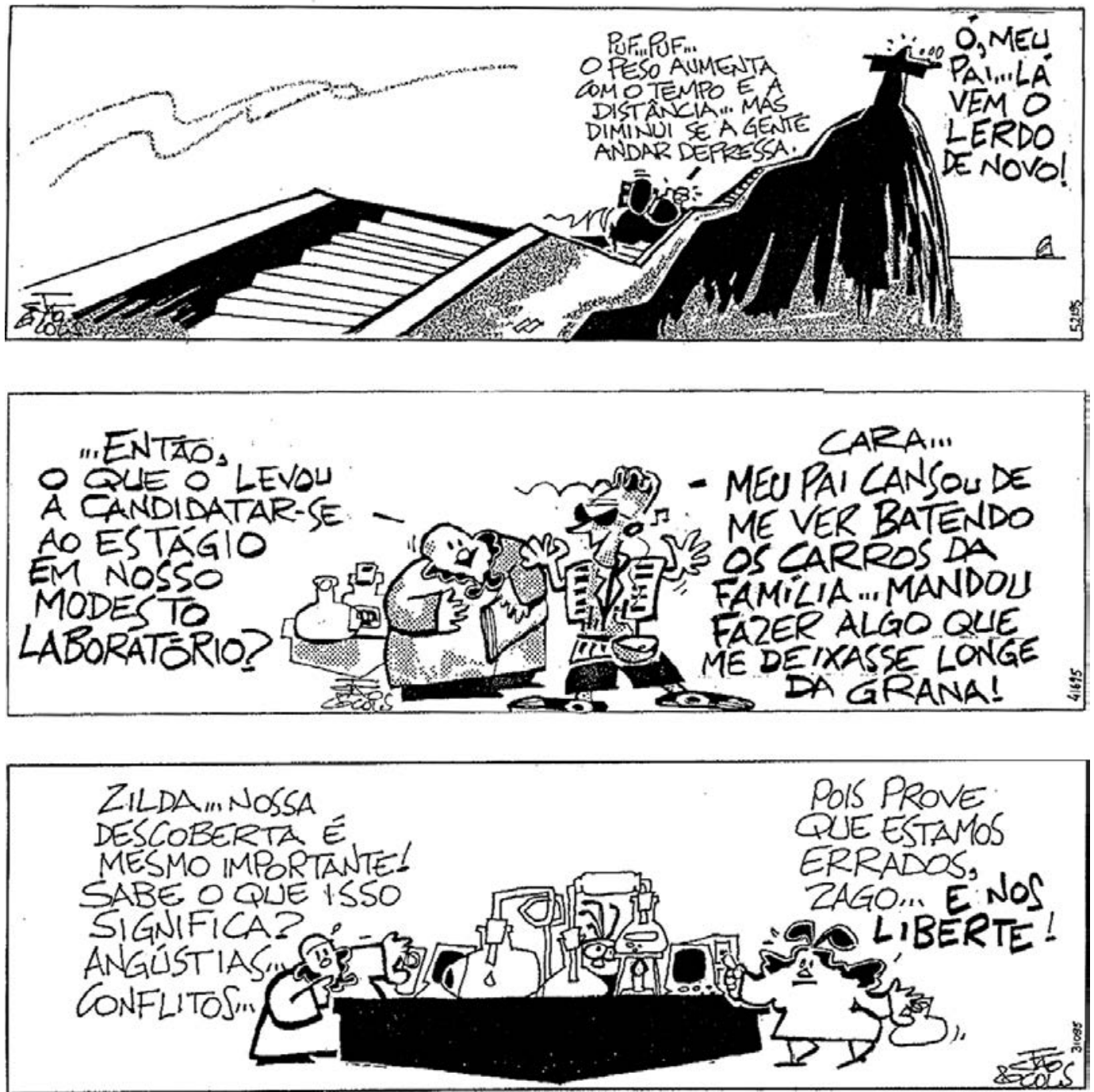

Figura 8: Tiras de João e Cols publicadas em Correio Popular, Campinas, 1994-2002

Os cientistas apresentavam os pesquisadores como anti-heróis, com suas facetas mais humanas e menos lisonjeiras, em vez do herói irreal e quase não humano do noticiário comum sobre ciência em jornais e revistas. Sua relevância histórica reside na possibilidade de ampliar a visão de ciência e de quem faz ciência. Em uma palestra proferida no nono Congresso de Comunicação Pública da Ciência e Tecnologia, em Seul, em maio de 2006, ao receber o prêmio pela Grande Contribuição Acadêmica em Comunicação Pública da Ciência e da Tecnologia, concedido pela The International Network on Public Communication of Science and Technology, Lévy-Leblond (2006, p.32) lançou este desafio:

Devemos abandonar essa representação equivocada da realidade, o legado da divisão que se fazia, no século XIX, entre os cientistas, detentores de um conhecimento geral e universal, e o público ignorante e indiferenciado, ao qual era preciso transmitir o conhecimento. Está mais do que na hora de nós, cientistas, mostrarmos um pouco mais de modéstia e admitirmos que nosso conhecimento é na realidade muito limitado. 
Os cientistas perseguiram essa visão mais ampla, realista e humana da ciência, marcada rotineiramente por incertezas e frustrações, entre as quais às vezes emerge uma descobertaconstrução-invenção notável. Os cientistas merecem destaque como produção brasileira que apresentava uma visão humanizada que retira da ciência, sem rejeitá-la, sua transcendência. A ciência é como a música, é obra humana. A ciência, ou melhor, as ciências são o que os cientistas fazem, e não constituem uma via privilegiada de acesso a um mundo transcendente (Da Costa Marques, 2012).

\section{NOTAS}

${ }^{1}$ Durante a segunda metade do século XX, fortes movimentos filosóficos, especialmente na França, a partir do trabalho de Michel Foucault, Gilles Deleuze, Félix Guatarri e Jacques Derrida, entre outros, exibiram poderosas ferramentas de desconstrução dos limites construídos pela epistemologia moderna. Também nas últimas décadas, na esteira de precursores como Karl Mannheim e Ludwik Fleck, pesquisadores do campo dos estudos de ciência e tecnologia e sociedade como Geoffrey Bowker, Michel Callon, Donna Haraway, Sheila Jasanoff, Bruno Latour, John Law, Donald MacKenzie, Emily Martin, Annemarie Mol, Susan Leigh Star, Marilyn Strathern, Sharon Traweek e Helen Veran exploraram e levaram adiante aquelas avenidas filosóficas, assim como o pragmatismo norte-americano de John Dewey e William James, para mostrar quão problemáticas podem ser as fronteiras entre o mundo dito das coisas em si, o mundo incorruptível de uma natureza transcendente, cuja descoberta resultaria de um trabalho despido de outro interesse que não fosse a busca da verdade, o mundo medido que Edmund Husserl chama de o mundo das subestruturas matematizadas, e o mundo dito dos homens entre si, o mundo corruptível de uma sociedade imanente, o mundo da vida, o mundo concreto dos corpos, no qual gozamos, sofremos, comemos, suamos, amamos e odiamos (Bijker, Hughes, Pinch, 1987; Bijker, Law, 1992; Law, Hassard, 1999). Os cientistas fazem as pontes para mostrar os cientistas no mundo da vida, levando-nos a questionar até que ponto esses dois mundos não estão imbricados em sua própria constituição. Optamos por referenciar as situações específicas ilustradas em Os cientistas ao livro de Bruno Latour (2000), cujo título já sugere a busca dessa imbricação, pelo fato de ele estar traduzido para o nosso idioma e ser hoje o mais citado representante das correntes (heterogêneas) de novas direções para a história e a sociologia das ciências e das tecnologias.

${ }^{2}$ Disponível em: http://www.phdcomics.com.

${ }^{3}$ Disponível em: http://jaogarcia.blog.uol.com.br.

${ }^{4}$ As descrições de Ferris (1990) sobre Newton, Galileu, Einstein, Planck e outros físicos são igualmente ricas.

\section{REFERÊNCIAS}

BARBOSA, Alexandre V.A.

História em quadrinhos sobre a história do Brasil na década de 50: a narrativa dos artistas da Ebal e outras editoras. Dissertação (Mestrado em Ciências da Comunicação) - Escola de Comunicações e Artes, Universidade de São Paulo, São Paulo. 2006.

BIJKER, Wiebe E.; HUGHES, Thomas P.; PINCH, Trevor J.

The social construction of technological systems: new directions in the sociology and history of technology. Cambridge: The MIT Press. 1987.

BIJKER, Wiebe E.; LAW, John.

Shaping technology/building society: studies in sociotechnical change. Cambridge: The MIT Press. 1992.
BOURDIEU, Pierre.

Os usos sociais da ciência: por uma sociologia clínica do campo científico. São Paulo: Editora Unesp. 2004.

BOURDIEU, Pierre.

Sobre a televisão. Rio de Janeiro: Jorge Zahar. 1997.

CABELLO, Karina S.A.; DE LA ROQUE, Lucia; SOUZA, Isabela C.F. de.

Uma história em quadrinhos para o ensino e divulgação da hanseníase. Revista Electrónica de Enseñanza de las Ciencias, v.9, n.1, p.225-241. 2010.

CARUSO, Francisco; SILVEIRA, Cristina. Quadrinhos para a cidadania. História, Ciências, Saúde-Manguinhos, v.16, n.1, p.217-236. 2009. 
CHO, Adrian.

General relativity: the comic book. Science, v.347, n.6226, p.1094-1095. 2015.

CIÊNCIA...

Ciência com muito humor. Imprensa, v.87, p.91. dez. 1994.

FERRIS, Timothy.

O despertar da Via Láctea: uma história da astronomia. Rio de Janeiro: Campus. 1990.

FIORAVANTI, Carlos Henrique.

Um enfoque mais amplo para o jornalismo científico. Intercom: Revista Brasileira de Ciências da Comunicação, v.36, n.2, p.315-332. 2013.

FREITAS, Ronald.

Os cientistas. Correio Popular, caderno C, p.2. 31 maio 1994.

FRIEDMAN, Meyer; FRIEDLAND, Gerald. As dez maiores descobertas da medicina. São Paulo: Companhia de Bolso. 2006.

GALHARDO, Caco; MEIGUINS, Alessandro. Heróis do clima: a aventura e a ciência por trás das mudanças climáticas. São Paulo: Planeta Sustentável; Abril. Disponível em: http://www. pactoglobal.org.br/Public/upload/ckfinder/files/ HQ_HEROIS_PACTOGLOBAL_PORT_BXok(1). pdf. Acesso em: 10 maio 2015. 2014.

GARCIA, João.

Os cientistas em quadrinhos. Disponível em: http://semana.mct.gov.br/index.php/content/ view/3135.html. Acesso em: 29 mar. 2015. 21 out. 2009.

GEISON, Gerald.

A ciência particular de Louis Pasteur. Rio de Janeiro: Editora Fiocruz; Contraponto. 2002.

GONZAGA, Luiziana A. et al.

A física dos super-heróis de quadrinhos (HQ).

Caderno de Física da UEFS, v.12, n.1, p.7-30. 2014.

HEY, Ana Paula.

Esboço de uma sociologia do campo acadêmico: a educação superior no Brasil. São Paulo: Edufscar. 2008.

\section{INFORMÁTICA...}

Informática em quadrinhos. Globo Ciência, v.55, p.63. fev. 1996.

INPA...

Inpa promove exposição de quadrinhos no Bosque da Ciência. Disponível em: http://www. brasil.gov.br/ciencia-e-tecnologia/2014/04/inpapromove-exposicao-de-quadrinhos-no-bosqueda-ciencia. Acesso em: 2 abr. 2015. 22 abr. 2014.

JÃO.

Os cientistas em quadrinhos. Brasília: Ministério da Ciência e da Tecnologia. 2005.
KANASHIRO, Marta M.; EVANGELISTA, Rafael de Almeida.

Ciência, comunicação e sociedade no Brasil, a narrativa do déficit. Journal of Science

Communication, v.3, n.4, p.1-5. Disponível em: http://jcom.sissa.it/sites/default/files/documents/ jcom0304(2004)F03_po.pdf. Acesso em: 17 jan. 2016. 2004.

LATOUR, Bruno.

Ciência em ação: como seguir cientistas e engenheiros sociedade afora. São Paulo: Editora Unesp. 2000.

LATOUR, Bruno; WOOLGAR, Steven.

Laboratory life: the construction of scientific facts. Princeton: Princeton University Press. 1986.

LAW, John; HASSARD, John (Ed.).

Actor network theory and after. Oxford: Blackwell; The Sociological Review. 1999.

LÉVY-LEBLOND, Jean-Marc.

Cultura científica: impossível e necessária. In: Vogt, Carlos (Org.). Cultura científica: desafios. São Paulo: Edusp; Fapesp. p.28-43. 2006.

MARQUES, Ivan da Costa.

Possibilidades de práticas ontológicas situadas. In: Kerbauy, Maria Teresa Miceli; Andrade, Thales Haddad Novaes de; Hayashi, Carlos Roberto Massao (Ed.). Ciência, tecnologia e sociedade no Brasil. Campinas: Alínea. p.67-86. 2012.

MENESES, Ulpiano T.B. de.

Fontes visuais, cultura visual, história visual: balanço provisório, propostas cautelares. Revista Brasileira de História, v.23, n.45, p.11-36. 2003.

MOTTA, Débora.

Livro de história em quadrinhos ajuda a popularizar os cientistas brasileiros. Disponível em: http://www.faperj.br/?id=2379.2.1. Acesso em: 29 mar. 2015. 7 fev. 2013.

OS CIENTISTAS...

Os cientistas em quadrinhos estreiam na próxima edição da Folhinha. Folha de S.Paulo. Disponível em: http://www1.folha.uol.com.br/multimidia/ videocasts/2009/02/507240-os-cientistas-emquadrinhos-estreiam-na-proxima-edicao-dafolhinha.shtml. Acesso em: 2 abr. 2015. $21 \mathrm{fev}$. 2009.

SHAPIN, Steven.

Never pure: historical studies of science as if it was produced by people with bodies, situated in time, space, culture, and society, and struggling for credibility and authority. Baltimore: Johns Hopkins University Press. 2010.

SILVA, Catarina C.

O mundo científico ao alcance de todos: a revista Ciência Popular e a divulgação científica no Brasil, 1948-1960. Dissertação (Mestrado em 
História) - Universidade Federal de Minas Gerais, Belo Horizonte. 2009.

UM ANO...

Um ano de Os cientistas. Globo Ciência, v.48, p.69. jul. 1995.

VOGT, Carlos; EVANGELISTA, Rafael de Almeida; KNOBEL, Marcelo.

Percepção pública da ciência: um esboço de análise e interpretação dos dados do questionário aplicado na cidade de Campinas, Brasil. Journal of Science Communication, v.2, n.3, p.1-18. Disponível em: http://jcom.sissa.it/sites/default/ files/documents/jcom0203(2003)A01_po.pdf. Acesso em: 17 jan. 2016. 2003.

ZANCHETTA, Luciene.

Série de quadrinhos trata ciência com humor. Ciência e Cultura, v.57, n.4, p.12-13. 2005.

\section{$\rightarrow \rightarrow \rightarrow<<<$}

